Article

\title{
Additional Indicators to Promote Social Sustainability within Government Programs: Equity and Efficiency
}

\author{
Adriana Acevedo Tirado *, Mariana Ruiz Morales and Odette Lobato-Calleros \\ Engineering Department, Universidad Iberoamericana Mexico City, Prolongación Paseo \\ de la Reforma 880, Lomas de Santa Fe, México C.P. 01219, Distrito Federal, Mexico; \\ E-Mails: mariana.ruiz@ibero.mx (M.R.M.); odette.lobato@ibero.mx (O.L.-C.) \\ * Author to whom correspondence should be addressed; E-Mail: adriana.acevedo@ibero.mx; \\ Tel.: +52-155-4232-7830.
}

Academic Editor: Marc A. Rosen

Received: 10 April 2015 / Accepted: 6 July 2015 / Published: 16 July 2015

\begin{abstract}
Social programs are crucial to reduce poverty and inequity in developing countries. The operation of social programs, however, cannot be improved with traditional engineering tools since these tools are designed to maximize profits: in social programs maximizing profits is not the objective, social sustainability is. Field research was conducted and it was found that the operation of social programs is considered more socially sustainable if it meets two criteria: Efficiency and Equity; in other words, if the program can help more people who need it the most. This paper proposes a methodology centered in the development of mathematical formulas for the concepts of Efficiency and Equity, so that, by being able to measure them, government programs operation can be enhanced with engineering tools. The methodology is illustrated with a case study, a subsidized milk distribution program in Mexico, called Liconsa. Once the formulas were developed and used in a simulation model for Liconsa, different policies were tested and their results regarding Efficiency and Equity were compared. Results showed the best policies for Liconsa are the balanced ones: where help is increased for beneficiaries, while cost reduction commitments are obtained. In the discussion it is argued how the developed Equity and Efficiency indicators help to understand the tradeoffs between the objectives in opposition: instead of analyzing dozens of indicators, some of them improving and others worsening, the two formulas allow to capture all effects into two objectives and evaluate decisions based on their integral impact. Conclusions show that the mathematical definition of Equity and Efficiency supports better and more informed decision making towards improving the social sustainability of the programs operation. The mathematical
\end{abstract}


definition of Equity and Efficiency and its use in engineering models helps balance the opposing objectives of social programs operation and promotes better and faster changes towards more socially sustainable programs.

Keywords: government programs supply chains; milk distribution; social programs; efficiency; equity; sustainability indicators; social sustainability

\section{Introduction}

Sustainability is a complex concept that has been widely studied by scholars and pursued by governments. The most widely spread concept of sustainability is the one given on the Brundtland's Report: "Humanity has the ability to make development sustainable to ensure that it meets the needs of the present without compromising the ability of future generations to meet their own needs" [1]. Several models and definitions for sustainability have been constructed after that [2]. Some definitions of sustainability combine global justice issues with ecological awareness [3]; others describe sustainability as "an important factor for competitiveness as it increases the added value of a company in terms of image and credibility" [4], and many argue that sustainability is supported by three main aspects: environment, economics, and the social component; but the truth is there is no one definitive concept of "sustainability" [2].

Out of the three mentioned pillars: environment, economics and social component, the social component has been the least studied and described [5,6]. Social sustainability can be defined as addressing the well-being not only of future, but also of current generations [7].

Social justice and social well-being are goals of local and federal programs, specifically in developing countries where poverty, malnutrition and inequality levels are of extreme concern [5], there is also the need of a structure that can help provide a fair distribution of resources. Unfortunately, it is common that these efforts do not bear results as expected and, in many nations, governments are far from being able to effectively address poverty, alimentary, and water issues [8].

In particular, the traditional engineering science has had good success in improving economic and environmental sustainability; however, it has not devoted enough efforts in increasing social sustainability [9], which is of concern since many human activities are related to and dependent upon products and processes engineers design and develop [10] and the world's most pressing and complex problems, inherently have engineering science dimensions [11].

The Industrial Engineering Department at Universidad Iberoamericana in Mexico City has found an area of opportunity in the domain of Supply Chain Management. A supply chain includes a "set of material and informational exchanges, starting from the acquisition of the raw materials to the delivery of the finished product to the final user, passing through a series of links that include suppliers, producers, carriers, warehouses, service providers, retailers and clients" [12]. A sustainable supply chain is defined as the management of material, information and capital flows as well as cooperation among companies along the supply chain while taking goals from all three dimensions of sustainable development: economic, environmental, and social [13]. 
Industrial Engineers are experts in improving the supply chain —also called "the operation" — so the way to promote social sustainability from the industrial engineering perspective is including the social sustainability concept in the supply chain. Given that the supply chain is the most expensive part of a product or company, a more socially sustainable supply chain will yield a more socially sustainable company, program, or product.

The traditional focus has been to study commercial enterprises' supply chains. However, in the current project we wanted to study supply chains operating within government programs; in particular, supply chains operating within alimentary social programs. The reason is that, according to the CONEVAL [14] in 2010, 28 million people in Mexico did not have access to proper nourishment and $13.6 \%$ of children under 5 years suffered from chronic malnutrition (27.4\% for indigenous children) [15]. Besides, almost half of all funds destined for social programs in Mexico are invested in alimentary programs (around 3.5 billion dollars per year). Therefore, alimentary programs are crucial in developing countries, where in order to build higher capacities, people have to meet their basic needs first (particularly alimentary needs).

There is a clear deficit in supply chain literature on social issues [13] and government programs chains have suffered from two different practices: either they have been considered similar to commercial or humanitarian chains, which is not appropriate since they have characteristics of their own that need to be tackled with customized approaches; or they have been analyzed from the perspective of the social sciences hence, not being subjected to engineering tools and principles. Both previous approaches have led to under-optimized government programs supply chains.

A research group was created and aimed to make government programs supply chains more socially sustainable. Field research was conducted and it was found that government supply chains have objectives in constant conflict. When actions are taken to improve certain objectives or indicators (such as cost, volume, etc.), other indicators (delivery times, equity, help given to beneficiaries, etc.) are affected. The decision as to which indicators are more important, or what actions will make the chain more socially sustainable, is not clear in most social programs. Therefore, after analyzing seven different government programs and performing extensive literature research, it was concluded that the first step must be the deliberation and definition over what indicators should guide the supply chain improvement. [16].

Several authors have worked to develop indicators of sustainability in different realms of production and services industries such as the Tourism Ecological Footprint [17], the Integrated Urban Sustainability Indicator [18], The Sustainable Infrastructure, Land-use, Environment and Transport Model (SILENT) [19], the framework of indicators for outdoor lighting systems [20], the Sustainability Index for the Automotive Industry [21] and the Life Cycle Sustainability Assessment [22]. Furthermore, literature provides the "indicator policy factsheets" for an easy use of indicators [23], methodologies for indicators development [24] and the Social Life Cycle Assessment methodology for a full analysis of social impacts of a product [7]. With broad objectives, perspectives, and research areas, sustainability science has not achieved a clear and unique methodology with universal indicators [10].

The objective of the current project is to propose indicators specific to measure the social sustainability of government programs supply chains. The proposed indicators do not pretend to be used in all kinds of supply chains - only in government programs Supply Chains — nor substitute the existent indicators systems [25], nor be able to measure how socially sustainable a product or a 
company can be during its whole life [4,21]. The purpose of the proposed indicators is to be able to measure how socially sustainable the supply chain of a government program is; in other words, how many people it can help (how Efficient the operation is) and what kind of people it can help (how Equitable the operation is).

Important authors have developed different performance management systems to ensure the supply chain is performing well [26-31]; the unique contribution of the current project is to complement the existent systems and offer two new indicators that will ensure that the supply chain is, also, performing in a socially sustainable way.

Still, the social sustainability of the entire program needs to be evaluated, but that is the job of economists, social scientists, and policy creators. Those players evaluate if the program is well designed, if the potential population is well defined, whether there are inclusion or exclusion errors (offering the benefit to people who do not deserve it or not offering it to those who do), the role that the program plays within the social programs universe, the true impact that the program has on poverty, malnutrition, education, opportunities, way of life, etc. The contribution of the current research is to help make sure that one important part of the government programs is socially sustainable: the supply chain.

\section{Government Programs Supply Chains-The Need for Efficiency and Equity}

A supply chain is formed by all those parts involved, directly or indirectly, in the delivery of products to clients [32]. According to Heizer [33], the costs of the supply chain, as a percentage of sales, are approximately $52 \%$ and in the United States, for example, supply chains contribute approximately $10 \%$ of the total gross domestic product. Therefore, by working on the supply chain, the performance of the whole organization can be significantly improved.

There are two types of supply chains studied in the literature: the commercial supply chain and the humanitarian supply chain. The commercial one has the objective to maximize profit or value created; it has a defined product and market, a known demand and a stable supply [12,32,34-37]. The humanitarian supply chain has the objective to minimize lost lives and alleviate suffering during natural disasters or armed conflicts; it is a short term chain, with short response times and total uncertainty in the products, amounts, and location of goods demanded [38].

The Industrial Engineering Department at Universidad Iberoamericana in Mexico City wanted to study a third type of supply chains: government programs' supply chains. The initial question was whether government programs supply chains were similar to commercial or humanitarian supply chains and whether the same engineering tools used to improve them could be used to improve government programs' Supply Chains. If the answer was positive, the concern was how to protect the social aspects of the program, while knowing that most engineering and mathematical tools usually do not address them (existent tools mainly focus on maximizing profits).

A literature review was conducted and numerous papers covering the supply chain topic and the social programs topic [39-44] were found. However, no studies covering both topics (supply chains and government social programs) were found. The previous situation is worrisome, since the most expensive part of most social programs' operation is the cost of the supply chain, therefore social 
programs should be studied from the engineering supply chain perspective- not only from the social sciences perspective - in order to improve them and reinforce their social sustainability.

Field research began in 2011 analyzing different social programs in Mexico. Observation trips and interviews were carried out in a two-year period including directly contacting seven directors of different social programs. The field research was aimed at understanding government programs supply chains, how they are operated and controlled, how performance management is conducted, and how well they meet their main goals and objectives. As a result, a new conception of supply chain was achieved: The Government Programs' Supply Chain, defined as the one whose main objective is to promote economic development and welfare for the population and create self-sufficiency and sustainability in the community in the long-term. Government Programs' Supply Chains are different from commercial and humanitarian chains; they have a defined product and list of beneficiaries and a very stable demand, similar to commercial chains, but their main objective is social, as in the humanitarian supply chains.

During the interviews, two main success factors or objectives were identified in all Government Programs Supply Chains: Efficiency, and Equity. Although the studied programs were very different in their characteristics and objectives (some were targeting nutrition while others poverty or school attendance, etc.), they all mentioned the need to operate more equitably and efficiently. They all explained that their programs alone could not reduce poverty or increase nutrition levels by themselves and even if they did, the effect of each program could not be isolated and measured. Being unable to measure the final impact of the program, they at least felt urged to make sure they were working in an efficient and equitable manner.

Socially sustainable programs should make sure they are using their resources properly in order to maximize the amount of social development promoted (they need to be Efficient); and they should make sure they are being fair [7] and they are helping those who need it most (they need to be Equitable). However, the task is not easy: it is impossible to make a program more equitable, and increase distribution to poorer places, when the program is evaluated based on costs. Similarly, it is not advisable to reduce prices for the benefit or increase help delivered per beneficiary, when the program is evaluated based on volume.

It was obvious that in order to make government chains more socially sustainable, two new indicators were needed. The indicators had to integrate all important indicators (cost, volumes, population served, distribution of beneficiaries, price, subsidy, budget, and so forth) in two formulas and measure their net effect in social sustainability. With these new indicators, all strategic decisions regarding the program operation can be evaluated based not only on their effects on individual indicators: volume, cost, budget, etc., effects which are always contradictory-some indicators improve while others become worse-but also based on their integral effect over the social sustainability of the operation, on Efficiency and Equity.

The two previous indicators make sense both from the social sciences and industrial engineering perspectives. First, it is impossible to tie changes in poverty, employment, or nutrition in the country to a specific government program. Therefore, government programs cannot be evaluated based only on their impact indicators, but also on operative indicators. Typical operative indicators include: cost, inventory, return on investment, volume produced, cycle times, revenue, range and response flexibility, etc. [25]. However, in government chains, operative indicators are in conflict and the path towards social 
sustainability is not clear: higher revenues mean higher prices for beneficiaries; low costs require less help for poor people; higher volumes require cheaper materials. The two proposed indicators: Efficiency and Equity, combine all operative indicators into two formulas and make clear, quantifiable, and comparable the net effect of any decision in the social sustainability of the operation.

Efficiency [26,27] and equity [28-31] had already been mathematically explained by some authors, but the descriptions did not fully apply to government chains. So in the case of Efficiency, a new definition was created based on the concept of "help" as opposed to volume. In the case of Equity, Coulter's Inequity index [28] was modified so that the concept of marginalization — as opposed to only poverty or potential beneficiaries - could guide the allocation of goods and improve the allocation fairness for government programs.

\section{Description of the Case Study: A Milk Distribution Social Program in Mexico}

With a population of over 120 million, Mexico is a country known to be in the category of "emergent economies", yet faces poverty and several related problems. $47 \%$ of the Mexican population lives in poverty to some extent and $19 \%$ of all population falls in the category of food poverty; i.e., does not earn enough money to meet basic nutritional needs [14]. Social programs are of particular importance to reduce poverty and inequity in Mexico and they have widely spread in the second half of the 20th century. Today, the social development agency in Mexico known as "Sedesol" manages an annual budget of almost 8 billion dollars and leads more than 133 social programs that include infrastructure programs, assistance programs, labor promotion programs, and alimentary programs; the last ones consuming almost $50 \%$ of Sedesol's budget [45].

The social program known as "Liconsa" is designed to improve nutrition levels amongst people whose income is below the welfare line; it distributes fortified milk at subsidized prices to more than 6 million beneficiaries per year. This milk delivery program is active since 1944 and is one of the most important social programs in the country with a current budget of 0.4 billion dollars per year. The target population for the program includes: children 6 months to 12 years old; female girls 13 to 15 years old; pregnant or lactating women; women between 45 and 59 years old; chronically ill or disabled people over 12 years old; and adults over 60 years old; all of them need to be rated below the poverty line. The program currently distributes more than 1 billion liters of milk per year, helping more than 6 million beneficiaries living in 5352 communities, half of them with less than 1500 inhabitants. This type of distribution represents a complex logistics challenge because of the roads and communications deficiencies of these communities [45].

The Liconsa program starts with the acquisition of milk from local farmers at a premium price, since local milk is usually more expensive than imported milk. Liconsa is in charge of pasteurizing or drying the milk and packing it in one of its 10 production plants in the country. The milk is distributed to almost 10,000 points of sale through 720 distribution routes that roughly cover 100,000 kilometers daily. Milk is sold to 6 million beneficiaries at subsidized prices. Finally, "commercial" milk is also sold to the general public at a higher price and the income generated by the selling of this product is used to subsidize part of the Liconsa social program. Consumers of the commercial milk, despite being called the "non-beneficiaries", actually obtain a benefit when they buy Liconsa milk, because it is cheaper than other milk brands in the market [14]. 
This program, like most social programs in Mexico, has been evaluated in terms of the program's impact on beneficiaries, the impact on the milk industry, on the economy, and on development indicators - such as poverty and malnutrition - and in terms of the complementarities and contribution within the social alimentary programs set. However, strategic decisions about the program have important effects on the social sustainability of the program's supply chain, and there is a lack of literature on methodologies to mathematically analyze this impact and improve the supply chain in general. For instance, Liconsa tries to continuously improve its supply chain operation, but it faces a constant conflict. Liconsa wants to reduce costs as much as possible in order to improve results such as: number of liters distributed, percentage of needed population covered, number of families covered, and budget spent on the social program. At the same time, the program aims to help the people who need it most. Therefore, the program needs to move out of the urban communities (where most of the milk is currently distributed) into rural communities - especially in south and southeast Mexico-where higher levels of marginalization and malnutrition are found. However, reaching these communities means a more expensive distribution system because of the roads and communication deficiencies found in rural areas. In other words, reducing costs and helping those who need it most are objectives in conflict.

Another conflict in the Liconsa chain arises with the milk acquisition. The program aims to keep helping local farmers by buying their milk but, by helping farmers, fewer beneficiaries can be helped since local milk is more expensive and less milk can be afforded with the same budget, i.e., helping local farmers is in conflict with helping more beneficiaries.

These kinds of conflicts are caused by the set of indicators used to evaluate the program chain operation: liters distributed, cost per liter, beneficiaries served, etc. Those indicators make sense when evaluating a commercial supply chain but not within a social program, whose objectives need to be socially sustainable.

As a result of the field research, it was found that most social programs face the same problem with their supply chain indicators, and it was necessary to define two additional indicators that could promote social sustainability within government program chains. Efficiency and Equity were confirmed as two constructs that could combine the effects of all existent indicators, and could help evaluate the net effect on social sustainability of any decision in the supply chain. Once the indicators were mathematically defined, an engineering tool called System Dynamics (a mathematical simulation tool, based on calculus, that helps analyze the relationships, feedback loops and behavior of systems in the long run [46]) was used to support the analysis of alternatives -regarding changes in budget, distribution of beneficiaries, amounts of local milk acquired, prices for the product, etc. Authors such as Iwaniec et al. [47] have demonstrated the advantages of using systems dynamics modeling approaches to analyze sustainability cases.

The proposed approach represents an important contribution to the field of government programs evaluation in Mexico, since Liconsa had already been evaluated according to its volume, cost, coverage, etc., but there were no indicators to measure the Efficiency and Equity - in other words, the net social sustainability_-resulting from any changes in the program. 


\section{Definition of Sustainability Indicators}

\subsection{Equity Definition}

Equity is a critical component of social sustainability. Equity can be broadly understood as a general sense of egalitarianism, or narrowly, as strict equality of income and wealth, although income distribution is a necessary but insufficient metric of equality [48]. Degradation of Equity (maldistribution) is defined by Stanton [48] as failure to achieve potential enlargements of social welfare via a more equal distribution of income or other resources. Equity in social programs reflects how fair resources are distributed according to the population needs and the characteristics of the goods or services provided [49]. The development of an Equity indicator, according to Mandell [29], depends on three decisions: the units to be distributed equitably (input units, output units or result units), the Equity unit (Equity per person, per family, per unit of need, per unit of merit, etc.) and the index to be used (Gini index, Coulter index, etc.). The index employed must obey the "transference principle" which states that a good Equity index must show improvement every time units of service are transferred from a richer group to a poorer group.

In the case of the Liconsa program, the objective is to be equitable in the amount of liters of milk distributed to the population (output units), even if it is more expensive to distribute to some groups than others. The amount distributed per community must be proportional to the number of potential beneficiaries present in that community; hence, the Equity unit to be used will be the Equity per potential beneficiaries. The index chosen was Coulter's Inequity Index [28], which measures the difference between what was delivered to each group and the amount that should have been delivered to that group according to the Equity unit. Coulter's Inequity index measures how imperfectly social help was distributed. This index was chosen because it is not more or less sensible to transferences performed in the low, medium or high levels of a distribution; as opposed to indexes based on Lorenz curves, which, being cumulative measurements, are more or less sensitive to transferences made at different levels of the distribution [29].

The proposed index to be used in order to measure Inequity in the Liconsa program is detailed in Formula (1).

$$
I=\frac{100 \sqrt{\sum_{i=1}^{n}\left[\left(\frac{X i}{\sum X i}\right) S U B R i-\left(\frac{\mathrm{POi}}{\sum \mathrm{POi}}\right) S U B i\right]^{\wedge} 2}}{\sqrt{1+\sum_{i=1}^{n}\left(\frac{\mathrm{POi}}{\sum \mathrm{POi}}\right)-2 \min \frac{\mathrm{POi}}{\sum \mathrm{POi}}}}
$$

$I=$ Inequity Index

$i=$ communities

$X i=$ Liters distributed in $\mathrm{i}$

POi $=$ Target population in $\mathrm{i}$

$S U B R i=$ Obtained subsidy in $\mathrm{i}$

$S U B i=$ Desired subsidy for $\mathrm{i}$

The difference between the proposed index and Coulter's index is that it suggests that different populations should receive different subsidies or amounts of help. The desired subsidy per community will depend on its degree of marginalization, with the argument that the criteria to help people through 
this social program should not be poverty but marginalization which is a broader concept that includes lack of access to food, education, and basic services [50]. With this new criterion, social sustainability for Liconsa is understood as giving equal opportunities regardless of the location of communities and the difficulty to reach them.

\subsection{Efficiency Definition}

A sustainable system must be efficient. In a general conception, Efficiency is how close observed performance is from desired performance [27]. There are definitions of Efficiency for different fields; in physics, Efficiency has to do with the relationship between the amount of energy invested and the amount of energy actually produced. In Production, Efficiency aims to use minimum resources to deliver the most results [49], so the main formula used for this indicator is $E=P / R$ ( $E=$ Efficiency, $\mathrm{P}$ = products obtained; $\mathrm{R}=$ resources invested) [26]. In the context of the milk delivery program Supply Chain, it was found that this definition of Efficiency is limited, as it would restrain performance to the accounting of the liters distributed as the result, and the program's budget as the resource.

After an in-depth analysis of the program and defining what were the desired outcomes, a new definition of "results" was necessary: the help provided. This would shift Efficiency into being measured by dividing the help provided over the amount of resources used, hence dividing the help provided to all stakeholders over the budget given to the program. Efficiency is indicated in percentage and gives a measure of the proportion of resources actually transformed into social help delivered to beneficiaries, to non-beneficiaries, and to local farmers. The amount of "help" delivered to beneficiaries and non-beneficiaries is calculated by multiplying the number of liters purchased times the savings obtained per liter. The savings refer to the difference in price between the milk found in the market and the milk bought from Liconsa. The more liters the program distributes, the more the help provided; the bigger the difference between the Liconsa price and the market price, the more the help provided. The amount of help given to producers is calculated subtracting the premium paid to local farmers $($ premium $=$ price of local milk - price of imported milk), times the number of liters acquired from them (see Formula (2)).

$$
\text { Efficiency }=\left[\sum_{i=0}^{n} \mathrm{ABi}+\mathrm{AP}+\mathrm{ANB}\right] / \mathrm{P}
$$

$\mathrm{AB}=$ Help to beneficiaries $=$ liters distributed $\times$ savings offered per liter

$\mathrm{AP}=$ Help to producers $=$ liters bought $\times$ premium paid per liter

$\mathrm{ANB}=$ Help to non-beneficiaries $=$ liters sold $\times$ savings offered per liter

$\mathrm{P}=$ annual budget (resources used)

$I=$ communities

With this new definition of Efficiency, social program's objective shifts from increasing number of liters and reducing cost, to maximizing the amount of help delivered to stakeholders, which is a broader concept that will allow the program to make better decisions to boost net Efficiency. For instance, the program may decide to increase help to local farmers and pay them more per liter of milk acquired. However, this would increase total acquisition costs for the program, and given a fixed budget, they would have to reduce the amount of liters delivered to the final beneficiaries. In the 
traditional Efficiency definition (results vs. resources), the help provided to local farmers was not included in the Efficiency formula and therefore, it would have never be considered as a suitable policy. However, with the new Efficiency definition that considers help to all stakeholders, the net effect on the indicator can be evaluated for any prospective decision, and policies can be selected in a broader sense towards social sustainability.

As can be observed, all main current Liconsa indicators, including volume, beneficiaries, cost, prices, subsidy, distribution of types of beneficiaries, etc. are included in one or both of the proposed indicators; therefore, decisions in the program chain can be evaluated according to their net impact on the social sustainability of the chain.

\section{Results for the Liconsa Program}

In order to demonstrate the usefulness of the defined indicators, a simulation model was created for the Liconsa Program. The model reproduces the relationships among the main indicators of the program, allowing us to estimate Equity and Efficiency for different future scenarios (see Figure 1).

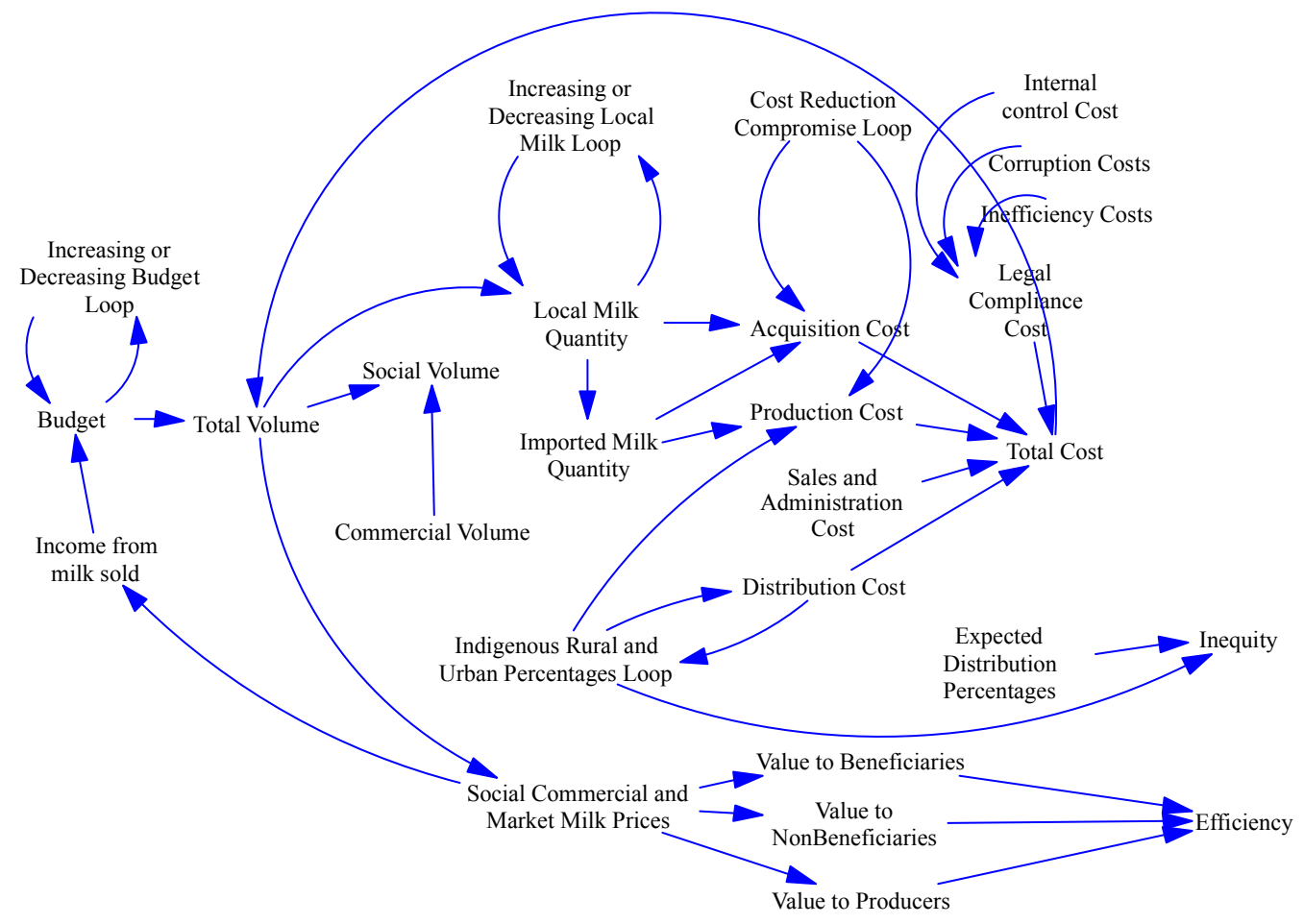

Figure 1. Simplified simulation model created for Liconsa.

The model was created using a System Dynamics software called Vensim. Through derivatives and integrals representing the relationships among variables, flows, and accumulations, the system dynamics model simulates the behavior of the system through time.

The scope of the current article is to show, through the model's results, the usefulness of the mathematical formulas defined for Equity and Efficiency, the model creation and validation is not in the scope, but the reader can be referred to [51] for further details on the model structure and characteristics. 
Thirteen different scenarios were run for the next 30 years, each of them modifying the Efficiency and Equity of the program chain through different program policies or parameters. Some policies included the modification of budgets; others modified the distribution of beneficiaries served (changing the percentage of indigenous, rural, and urban communities); some others changed the sales price for the milk; and others varied the amount of milk acquired from local farmers (see Table 1).

Table 1. Scenarios run for Liconsa and the parameters changed in the model for each one.

\begin{tabular}{|c|c|c|c|c|c|c|c|c|c|c|c|c|c|c|}
\hline Parameters & $\stackrel{\mathscr{E}}{\mathscr{\Xi}}$ & 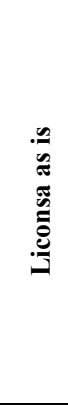 & 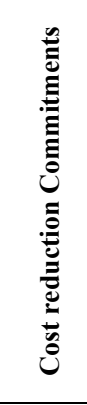 & 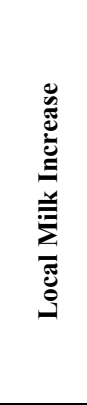 & 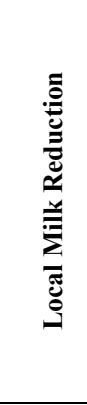 & 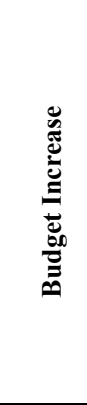 & 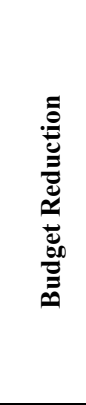 & 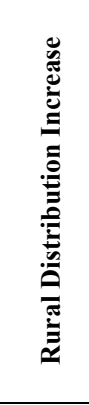 & 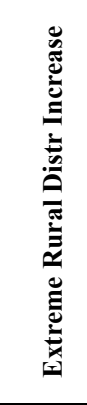 & 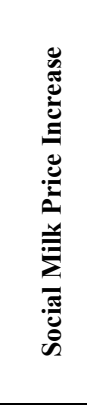 & 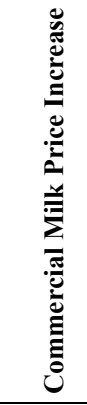 & 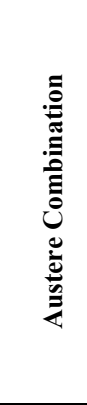 & 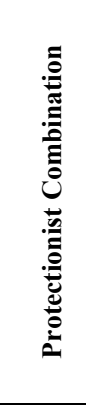 & 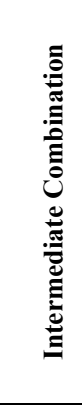 \\
\hline$\%$ Budget increase & \%/año & 0 & 0 & 0 & 0 & 0.01 & -0.01 & 0 & 0 & 0 & 0 & -0.01 & 0.01 & 0 \\
\hline Liconsa price (social milk) & \$/litro & 4.5 & 4.5 & 4.5 & 4.5 & 4.5 & 4.5 & 4.5 & 4.5 & 5.5 & 4.5 & 4.5 & 4.5 & 4.5 \\
\hline Liconsa price (commercial milk) & \$/litro & 8.5 & 8.5 & 8.5 & 8.5 & 8.5 & 8.5 & 8.5 & 8.5 & 8.5 & 9.5 & 9.5 & 8.5 & 9.5 \\
\hline Market milk average price & \$/litro & 11.3 & 11.3 & 11.3 & 11.3 & 11.3 & 11.3 & 11.3 & 11.3 & 11.3 & 11.3 & 11.3 & 11.3 & 11.3 \\
\hline$\%$ milk acquired from local farmers & $\%$ & 63 & 63 & 90 & 30 & 63 & 63 & 63 & 63 & 63 & 63 & 30 & 90 & 90 \\
\hline Cost reduction for local milk & $\% /$ year & 0 & -0.01 & -0.01 & -0.01 & -0.01 & -0.01 & -0.01 & -0.01 & -0.01 & -0.01 & -0.01 & -0.01 & -0.01 \\
\hline Cost reduction for production & \%/año & 0 & -0.01 & -0.01 & -0.01 & -0.01 & -0.01 & -0.01 & -0.01 & -0.01 & -0.01 & -0.01 & -0.01 & -0.01 \\
\hline Increase in indigenous distribution & \%/año & 0 & 0 & 0 & 0 & 0 & 0 & 0.01 & 0.02 & 0 & 0 & 0.01 & 0.02 & 0.01 \\
\hline
\end{tabular}

The first scenario ("Liconsa as is"), where Liconsa keeps operation unchanged for the next 30 years (this scenario includes no budget increases, current milk prices are maintained unchanged, 63\% of milk is acquired from local farmers, no cost reductions are expected, see Table 1), showed an average Efficiency of $77 \%$ and an expected Inequity index of $41 \%$ for the next 30 years. These figures allowed us to test different future scenarios and evaluate them based on how they improved or worsened the efficiency and equity of the current program. For instance, scenario 2 ("Cost reduction commitments") proposed $1 \%$ annual cost reduction in the milk acquisition and production areas (all other parameters stayed the same). This scenario increased Efficiency in the sense that costs were reduced and more help could be given to beneficiaries, but it reduced Efficiency at the same time, since lower prices were paid to local milk producers and "help to producers" decreased. The calculated net Efficiency for this scenario was $2 \%$ better than the "Liconsa as is" scenario, while Inequity stayed the same, suggesting that this scenario would be preferred vs. keeping the current operation. Table 1 shows the exact parameters that were used in each scenario and allows us to understand which policies each scenario is trying to simulate.

Of all the scenarios simulated, the one that gave the best results was "the intermediate combination", consisting of an Increase in local milk acquired (from 63\% to 90\%) and an increase in rural distribution ( $1 \%$ annual increase) with the condition that prices for local milk and its processing costs are reduced 2\% annually during the next 10 years. Efficiency for this scenario increased 3\% and Equity improved $27 \%$ compared to the current scenario. The results of all scenarios are summarized in Table 2. 
Table 2. Results for each scenario, calculated as percentage improvement vs. "Liconsa as is" scenario.

\begin{tabular}{|c|c|c|c|c|c|c|c|c|c|c|c|c|c|}
\hline & 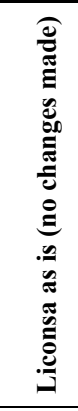 & 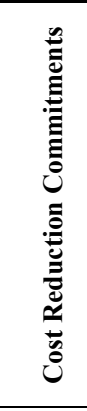 & 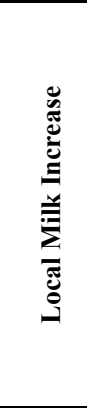 & 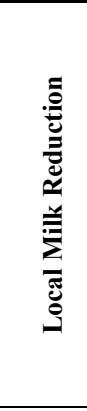 & 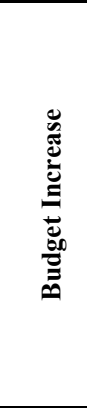 & 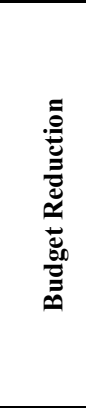 & 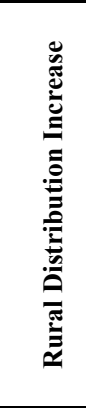 & 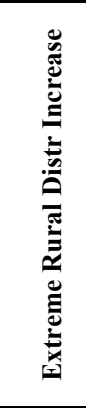 & 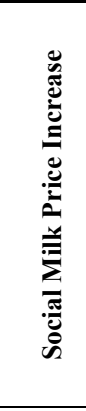 & 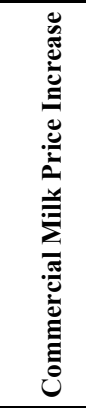 & 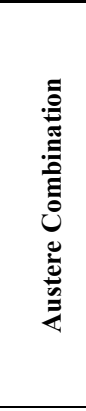 & 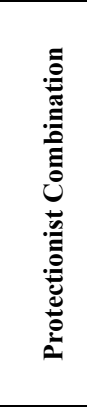 & 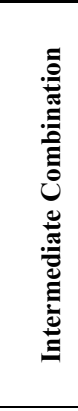 \\
\hline Liters distributed (liters/year) & 0.00 & 0.15 & 0.14 & 0.12 & 0.33 & -0.01 & 0.12 & 0.09 & 0.85 & 0.2 & 0 & 0.05 & 0.39 \\
\hline Cost of distribution (\$/year) & 0.00 & -0.13 & -0.13 & -0.10 & -0.30 & 0.01 & -0.21 & -0.27 & -0.77 & -0.18 & -0.09 & -0.24 & -0.49 \\
\hline Unit cost per liter (\$/liter) & 0.00 & 0.05 & 0.04 & 0.04 & 0.05 & 0.04 & 0.04 & 0.03 & 0.06 & 0.05 & 0.03 & -0.04 & 0.09 \\
\hline Efficiency & 0.00 & 0.02 & 0.03 & 0.00 & 0.04 & 0.00 & 0.01 & -0.01 & -0.07 & 0.01 & -0.04 & -0.01 & 0.03 \\
\hline Equity & 0.00 & 0.00 & 0.00 & 0.00 & 0.00 & 0.00 & 0.27 & 0.21 & 0.00 & 0.00 & 0.27 & 0.21 & 0.27 \\
\hline
\end{tabular}

\section{Discussion}

All insights obtained from the 13 tested scenarios are important for the program decision making process. For instance, the only way the program can improve Equity is through policies that increase the amount of rural population served. However, the increase must be moderate to avoid a spike in distribution costs and a reduction in volumes due to lack of money among rural beneficiaries. To increase help to farmers, the best path is through a reduction of costs in the program that can lead to an increase in volume produced, and, therefore, an increase in milk acquired. Sales price increases are not recommended; even though this practice increases income, it reduces efficiency and help to beneficiaries.

Before Efficiency and Equity were mathematically defined, different strategic decisions in the program were difficult to make because, as it can be observed in Table 2, all decisions or scenarios could improve some indicators but worsen others, and the criteria to decide which indicator was more important was not clear. For instance, the policy to acquire milk from local farmers has changed several times: under one administration, local milk was increased, and since overall costs increased, the following administration took the decision to drastically reduce the amount of milk. The following administration, worried by farmers' complaints, increased the amount of milk bought again, and the cycle started all over again. Since the amount of milk bought from local farmers is controversial, the proposed model helps the decision making process by balancing effects of decisions. In other words, with the two developed formulas, the mathematical model measures the net impact of all indicators on Equity and Efficiency and proves that the right decision is to increase the amount of local milk acquired, because that policy is 3\% more efficient than keeping the current amount of milk or reducing it.

The inclusion of all impacts fall under two indicators: Efficiency and Equity, with all effects weighted within those formulas allows to evaluate all scenarios under an objective and integral approach, according to the real objective of the program: to help more people who need it most.

The Equity and Efficiency indicators help to understand the tradeoffs between the objectives in opposition. Instead of analyzing dozens of indicators, some of them improving and others worsening, 
the two formulas allow to capture all effects into two objectives and evaluate decisions based on their integral impact. Besides, instead of just knowing that the program might become less or more equitable with a specific decision, with the proposed formulas, one can understand exactly in what percentage each objective will be affected, and whether it is worthwhile based on the percentage by which the other objective will be modified.

Regarding the validity of the proposed supply chain performance measurement system, Beamon [34] explains that effective measurement systems must be inclusive, universal, measurable, and consistent. The Equity and Efficiency indicators this article proposes, meet all four criteria: They are inclusive, because all current social program indicators, including resources measurements (budget, program income) and output measurements (volume, \% coverage, etc.) are considered within the Equity and Efficiency formulas. They are universal, since they allow comparison under different scenarios and policies applied to the supply chain. They are measurable, since for the first time in literature, Equity is quantified and included in a supply chain improvement model. Finally, they are consistent with the strategic goals of the program: the developed indicators contribute to help more people (through Efficiency) who need it the most (through Equity).

\section{Conclusions}

Social government programs are crucial in the battle against poverty and inequity in countries like Mexico. The government spends billions of dollars on social programs and the most expensive part of their operation is the supply chain, so focusing engineering tools on the improvement of social programs' supply chains is very important.

However, government programs Supply Chains cannot be improved with the same tools and methodologies used in commercial supply chains. Government programs can have more socially sustainable operations if they are more efficient and able to use the available resources to help the biggest quantity of beneficiaries possible and if they are more equitable by using the resources in a way they can help the people who need it most.

Equity and Efficiency are usually in conflict within government programs chains. Most programs become more expensive (and less efficient) every time they want to be more equitable and serve more needed beneficiaries. Several engineering methodologies serve to optimize and balance opposite objectives in supply chains, but before any engineering methodology can be used, the concepts of Equity and Efficiency need to be expressed as quantitative indicators, rather than qualitative concepts.

The Liconsa case provided an example of how mathematical conceptions of Efficiency and Equity may be incorporated into measuring and evaluating possible social sustainability efforts made by government.

The research conducted sets the basis for a methodology that complements existing assessments of social sustainability in supply chains. The proposed methodology allows the selection of explanatory variables and their inclusion in the mathematical definition of Efficiency and Equity in order to use engineering methodologies to solve the conflict among them and make the government programs chain more socially sustainable.

There are numerous opportunities where mathematical models can improve supply chains, but the challenge in Government Programs Supply Chains is to define social sustainability indicators that truly reflect what is needed to be achieved, so that mathematical models used can keep their focus 
on the development of communities - and not on costs, volumes, or profits, as they usually do in commercial chains.

The proposed methodology can be used with other governmental programs, not only with alimentary programs, but any social program with a physical supply chain (with acquisition, processing, and distribution operations). The requirement is the definition of mathematical formulas customized for the Efficiency and Equity of the chain under study. Formulas will be very similar to those developed for Liconsa, since the concepts of Equity and Efficiency will not change; only the particular indicators affecting the measurement of "help" or the definition of equitable distribution. The present proposal is a step towards better performance of Government Programs Supply Chains, highly needed in developing countries, to build a fairer and more equitable society.

\section{Acknowledgments}

The authors would like to acknowledge the Liconsa program and local and federal social programs authorities for their support in providing information for this research.

\section{Author Contributions}

The design, data collection, and execution of the research were conducted by the first author; second and third authors provided substantial contributions to the focus, scope, and characteristics of the research.

\section{Conflicts of Interest}

The authors declare no conflict of interest.

\section{References}

1. Brundtland, G. Report of the World Commission on Environment and Development: Our Common Future. Available online: http://www.un-documents.net/our-common-future.pdf (accessed on 20 May 2015).

2. Hamiti, S.W.; Wydler, H. Supporting the Integration of Sustainability into Higher Education Curricula-A Case Study from Switzerland. Sustainability 2014, 6, 3291-3300.

3. Beecroft, R.; Schmidt, J.C. Method-Based Higher Education in Sustainability: The Potential of the Scenario Method. Sustainability 2014, 6, 3357-3373.

4. Arcese, G.; Lucchetti M.C.; Merli, R. Social Life Cycle Assessment as a Management Tool: Methodology for Application in Tourism. Sustainability 2013, 5, 3275-3287.

5. Rogers, S.H.; Gardner, K.H.; Carlson C.H. Social Capital and Walkability as Social Aspects of Sustainability. Sustainability 2013, 5, 3473-3483.

6. Wolbring, G.; Rybchinski, T. Social Sustainability and Its Indicators through a Disability Studies and an Ability Studies Lens. Sustainability 2013, 5, 4889-4907.

7. Lehmann, A.; Russi, D.; Bala, A.; Finkbeiner, M.; Fullana-i-Palmer, P. Integration of Social Aspects in Decision Support, Based on Life Cycle Thinking. Sustainability 2011, 3, 562-577.

8. Hansmann, R. "Sustainable learning": An Introduction to the Concept and Its Motivational Aspects. Sustainability 2010, 2, 2873-2897. 
9. Scott, R. Education for Sustainability through a Photography Competition. Sustainability 2014, 6, 474-486.

10. Nagel, R.L.; Pappas, E.C.; Pierrakos, O. On a Vision to Educating Students in Sustainability and Design-The James Madison University School of Engineering Approach. Sustainability 2012, 4, $72-91$.

11. Knowlton, J.L.; Halvorsen, K.E.; Handler, R.M.; O’Rourke, M. Teaching Interdisciplinary Sustainability Science Teamwork Skills to Graduate Students Using In-Person and Web-Based Interactions. Sustainability 2014, 6, 9428-9440.

12. Council of Supply Chain Management Professionals (CSCM). Glossary of Terms. Available online: http://cscmp.org/digital/glossary/glossary.asp (accessed on 10 March 2012).

13. Seuring, S.; Martin, M. From a literature review to a conceptual framework for sustainable supply chain management. J. Clean. Prod. 2008, 16, 1699-1710.

14. CONEVAL (Consejo Nacional de Evaluación de la Política de Desarrollo Social). Poverty Executive Report and Program Evaluations, "Informe Ejecutivo de Pobreza", 2007. Available online: http://www.coneval.gob.mx/ (accessed on 2 June 2014).

15. Encuesta Nacional de Salud y Nutrición. Informe, 2012. Available online: http://ensanut.insp.mx (accessed on 8 November 2013).

16. Miller, T.R.; Wiek, A.; Sarewitz, D.; Robinson, J.; Olsson, L.; Kriebel, D.; Loorbach, D. The future of sustainability science: A solutions-oriented research agenda. Sustain. Sci. 2014, 9, 239-246.

17. Chen, H.-S. The Establishment and Application of Environment Sustainability Evaluation Indicators for Ecotourism Environments. Sustainability 2015, 7, 4727-4746.

18. Shen, L.; Kyllo, J.M.; Guo, X. An Integrated Model Based on a Hierarchical Indices System for Monitoring and Evaluating Urban Sustainability. Sustainability 2013, 5, 524-559.

19. Yigitcanlar, T.; Dur, F. Developing a Sustainability Assessment Model: The Sustainable Infrastructure, Land-Use, Environment and Transport Model. Sustainability 2010, 2, 321-340.

20. Jägerbrand, A.K. New Framework of Sustainable Indicators for Outdoor LED (Light Emitting Diodes) Lighting and SSL (Solid State Lighting). Sustainability 2015, 7, 1028-1063.

21. Onat, N.C.; Kucukvar, M.; Tatari, O. Towards Life Cycle Sustainability Assessment of Alternative Passenger Vehicles. Sustainability 2014, 6, 9305-9342.

22. Salvado, M.F.; Azevedo, S.G.; Matias, J.C.O.; Ferreira, L.M. Proposal of a Sustainability Index for the Automotive Industry. Sustainability 2015, 7, 2113-2144.

23. Hák, T.; Janoušková, S.; Whitby, A.; Abdallah, S.; Kovanda, J. Indicator Policy Factsheets: A Knowledge Brokerage Tool. Sustainability 2015, 7, 3414-3429.

24. Waas, T.; Hugé, J.; Block, T.; Wright, T.; Benitez-Capistros, F.; Verbruggen, A. Sustainability Assessment and Indicators: Tools in a Decision-Making Strategy for Sustainable Development. Sustainability 2014, 6, 5512-5534.

25. Beamon, B.M. Measuring supply chain performance. Int. J. Oper. Product. Manag. 1999, 19, 275-292.

26. Koontz, H. Essentials of Management; TATA McGraw Hill: New Delhi, India, 2009.

27. Grosskopf, S. The Measurement of Efficiency of Production; Kluwer: Hingham, MA, USA, 1985; pp. 1-5. 
28. Coulter, P. Measuring the Inequity of Urban Public Services: A Methodological Discussion with Applications. Policy Stud. J. 1980, 8, 683-698.

29. Mandell, M. Modelling effectiveness-equity trade-offs in public service delivery systems. Manag. Sci. 1991, 37, 467-482.

30. Mokate, K. Social Management, Gerencia Social: Un Enfoque Integral para la Gestión de Políticas y Programas, Interamerican Development Bank, Working Documents Series I-56. Available online: http://www.iadb.org/wmsfiles/products/publications/documents/2220394.pdf (accessed on 20 June 2014).

31. Kamat, S. Populism Repackaged: The World Bank's Perspective on Equity and Youth. Dev. Change 2007, 38, 1209-1218.

32. Chopra, S.; Meindl, P. Supply Chain Management Administración de la Cadena de Suministro, 3rd ed.; Pearson Education: México, México, 2008; p. 552.

33. Heizer, J.; Render, B. Operations Management Principles. In Principios de Administración de Operaciones, 7th ed.; Pearson: México, México, 2009; p. 752.

34. Beamon, B. Performance Measurement in humanitarian relief chains. Int. J. Public Sector Manag. 2008, 21, 4-25.

35. Davidson, A. Key Performance Indicators in Humanitarian Logistics, 2006. Available online: http://www.fritzinstitute.org (accessed on 10 March 2012).

36. Georgiadis, P.; Besiou, M. Environmental and Economical sustainability of WEEE closed-loop supply chains with recycling: A system dynamics analysis. Int. J. Adv. Manufact. Technol. 2010, 47, 475-493.

37. Rabelo, L.; Sarmiento, A.; Jones, A. Stability of the Supply Chain Using System Dynamics Simulation and the Accumulated Deviations from Equilibrium. Model. Simul. Eng. 2011, 2011, 1-10.

38. Apte, A. Chapter 3: Design of Humanitarian Logistics, in Humanitarian Logistics, Foundations \& Trends in Technology, Information \& Operations Management; Now Publishers: Norwell, MA, USA, 2009; pp. 18-28.

39. Kumar, S.; Nigmatullin, A. A system dynamics analysis of food supply chains - Case study with non-perishable products. Simul. Model. Pract. Theory 2011, 19, 2151-2168.

40. Cuenca, M. Evaluación de los expendios de alimentos utilizados por diferentes programas de alimentación, revisión sistemática. Anales Venez. Nutr. 2011, 24, 86-91.

41. Corrales, J. Sociedad y Evaluación de Programas Sociales en el Realismo Crítico: Una Revisión Crítica. Investig. Desarro. 2007, 15, 170-207.

42. Matos, R. Una propuesta para la evaluación de programas sociales: Lineamientos generales. Gac. Lab. 2005, 11, 95-118.

43. World Bank Independent Evaluation Group. The measurement and evaluation system in Mexico. In El Sistema de Medición y Evaluación de México: Un Salto del Nivel Sectorial al Nacional; World Bank Independent Evaluation Group: Mexico City, Mexico, 2009.

44. Singh, N. Expert system prototype of food aid distribution. Asia Pacific J. Clin. Nutr. 2007, 16 (Suppl. 1), 116-121.

45. Secretaría de Desarrollo Social. Metaevaluación 2007-2012, 2013. Available online: http://www.2006-2012.sedesol.gob.mx/en/SEDESOL/Meta_Evaluacion_2007-2012 (accessed on 16 November 2013). 
46. Sterman, J.D. Business Dynamics: Systems Thinking and Modeling for a Complex World; Irvin McGrawHill: New York, NY, USA, 2000.

47. Iwaniec, D.M.; Childers, D.L.; van Lehn, K.; Wiek, A. Studying, Teaching and Applying Sustainability Visions Using Systems Modeling. Sustainability 2014, 6, 4452-4469.

48. Stanton, E. The Tragedy of Maldistribution: Climate, Sustainability, and Equity. Sustainability 2012, 4, 394-411.

49. Athanassopoulos, A.D. Decision support for target-based resource allocation of public services in multiunit and multilevel systems. Manag. Sci. 1998, 44, 173-187.

50. CONAPO (Consejo Nacional de Población), Marginality Index, “Índice de Marginación”, 2012. Available online: http://www.conapo.gob.mx/es/CONAPO/Indices_de_Marginacion (accessed on 2 February 2012).

51. Acevedo, A.; Lobato-Calleros, O.; Ruiz-Morales, M. Marco para Uso de Dinámica de Sistemas en Mejora de Cadenas Sociales, Congreso Internacional de Logística y Cadena de Suministro. In Proceedings of the International Congress on Logistics 2014 (CILOG 2014), Mexico City, Mexico, 16 October 2014.

(C) 2015 by the authors; licensee MDPI, Basel, Switzerland. This article is an open access article distributed under the terms and conditions of the Creative Commons Attribution license (http://creativecommons.org/licenses/by/4.0/). 